\title{
ANALYSIS OF THE EFFECT OF BYPASS RATIO ON PERFORMANCE ENGINE CFM56-5A1 IN CRUISING CONDITIONS
}

\author{
Opri Surya Yustinoto \\ Program Studi Teknik Dirgantara \\ Sekolah Tinggi Teknologi Adisutjipto \\ Jl. Janti Blok R Lanud Adisutjipto Yogyakarta \\ suryaopri@gmail.com
}

\begin{abstract}
The value of engine performance is known to decrease and increase with increasing and decreasing variation of the value of the parameter bypass ratio, so that if the value of these parameters is greater, then the fuel consumption when the aircraft operates will be less and the thrust will decrease. In addition to changing the value of the specific fuel consumption due to the influence of the bypass value, variations in altitude are also very influential where the higher the aircraft, the resulting specific fuel consumption value will be smaller
\end{abstract}

Keywords : Bypass Ratio, Performance Engine, CFM56-5A1, Cruising.

\section{Latar Belakang}

Kementerian Perhubungan Indonesia, melalui Jurnal Proyeksi Pergerakan Pesawat Internasional dan Domestik pada tahun 2019, mengatakan bahwa prediksi laju perkembangan pergerakan pesawat naik pesat dari tahun 2017 sampai 2026 dengan laju kenaikan hingga 90\%. Hal ini didasari oleh berkembangnya kebutuhan transportasi udara baik domestik maupun internasional sehingga kebutuhan akan pesawat yang lebih efisien akan lebih banyak [1][2].

Pada engine pesawat terbang, aliran bypass sangat berpengaruh terhadap thrust dan specific fuel consumption karena sangat membantu supaya engine tersebut mencapai output yang efisien, sebab pada saat pesawat udara beroperasi yaitu terbang di ketinggian terbang cruising maka temperatur udaranya sangat rendah sehingga sangat sulit untuk dilakukan pembakaran. Oleh karena itu peningkatan atau penurunan bypass ratio akan berpengaruh pada performa engine pesawat udara[1][4].

Guna untuk mengetahui pengaruh peningkatan atau penurunan bypass ratio pada performa engine yakni meliputi specific fuel consumption. Maka pada tugas akhir ini akan dilakukan perhitungan untuk mengetahui pengaruh bypass ratio terhadap performance engine yang dimiliki oleh engine CFM 56-5A1 menggunakan metode parametric cycle analysis of real engine, kemudian melihat nilai hasil perhitungan pada kondisi cruising dengan inputan variasi bypass ratio yang berbeda[3]. 


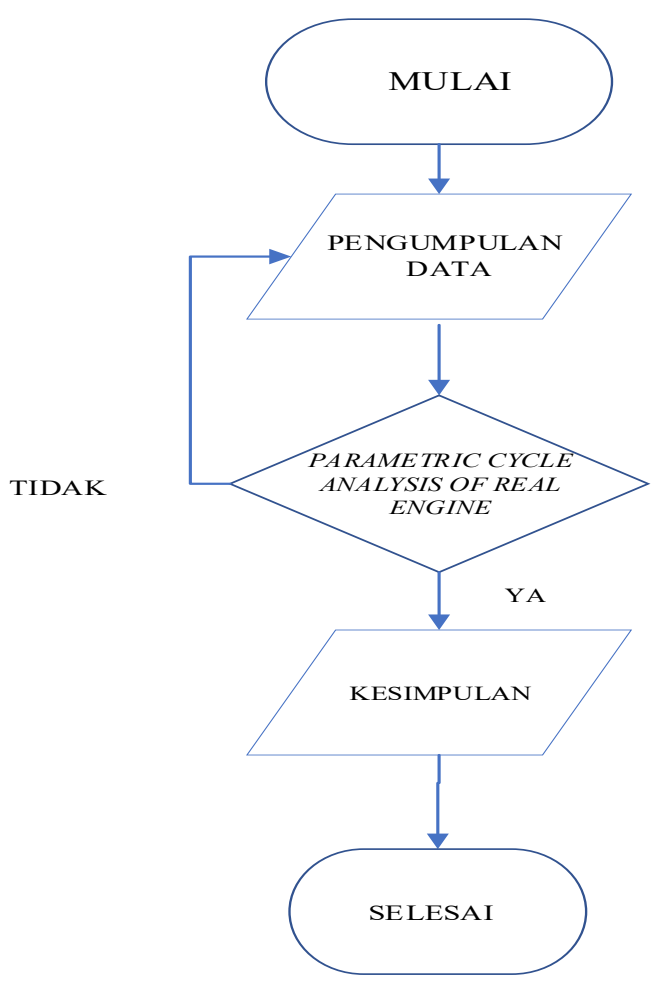

Gambar 1. Diagram Alir Penelitian

\section{Metodologi Penelitian}

Proses pelaksanaan penelitian ini sebagaimana diilustrasikan pada Gambar 1. Penjelasan mengenai flowchart penelitian adalah sebagai berikut :

a. Mulai, Penulis menentukan tema dan konsep sebelum menyusun jurnal.

b. Pengumpulan Data, mengelompokkan parameter-parameter dari data engine yang sudah ditentukan,

c. c cycle analysis digunakan untuk menghitung parameter performa engine seperti spesifc fuel consumption dengan batasan limitasi desain seperti suhu turbin maksimum yang diijinkan dan efisiensi komponen yang dapat dicapai, dengan perubahan nilai bypass ratio dengan variasi ketinggian 35.000, 36.000 dan 37.000 feet.

d. Kesimpulan, diperoleh setelah semua data sudah di hitung dan di analisis.

\section{Hasil dan Pembahasan}

Dibawah ini merupakan parameter dari engine CFM56-5A1 [2] yang sudah didapatkan dapat di lihat pada table 1,2 dan 3 sebagai berikut:

Tabel 1 Data Input Parameter Ketinggian 35.000 feet

\begin{tabular}{|c|c|c|}
\hline Simbol & Nilai & Satuan \\
\hline$M_{0}$ & 0,8 & - \\
\hline$T_{0}$ & 393,93 & ${ }^{\circ} \mathrm{R}$ \\
\hline$T_{t 4}$ & 2769 & ${ }^{\circ} \mathrm{R}$ \\
\hline$P_{0}$ & 3,46 & Psi \\
\hline$\alpha$ & 6 & - \\
\hline
\end{tabular}




\begin{tabular}{|c|c|c|}
\hline$\dot{m}_{0}$ & 852 & $\mathrm{lbm} / \mathrm{s}$ \\
\hline$\pi_{d \max }$ & 0,995 & - \\
\hline$\pi_{b}$ & 0,95 & - \\
\hline$\pi_{f n}$ & 0,99 & - \\
\hline$\pi_{n}$ & 0,995 & - \\
\hline$\pi_{c}$ & 26,5 & - \\
\hline$\pi_{f}$ & 1,55 & - \\
\hline$e_{c}$ & 0,90 & - \\
\hline$e_{f}$ & 0,89 & - \\
\hline$e_{t}$ & 0,89 & - \\
\hline$\gamma_{c}$ & 1,4 & $\mathrm{Btu} /\left(\mathrm{lbm} .{ }^{\circ} \mathrm{R}\right)$ \\
\hline$C_{p c}$ & 0,24 & - \\
\hline$\gamma_{t}$ & 1,333 & $\mathrm{Btu} /\left(\mathrm{lbm} .{ }^{\circ} \mathrm{R}\right)$ \\
\hline$C_{p t}$ & 0,276 & $\mathrm{Btu} /(\mathrm{bm}$ \\
\hline$h_{P R}$ & 18.400 & $1 \mathrm{~b} . \mathrm{ft} /\left(\mathrm{lbf} . \mathrm{s}^{2}\right)$ \\
\hline$g_{c}$ & 32,174 & - \\
\hline$\eta_{b}$ & 0,999 & - \\
\hline$\eta_{m}$ & 0,995 & - \\
\hline $\mathrm{P} 0 \mathrm{P9}$ & 0,9 & - \\
\hline $\mathrm{P} 0 \mathrm{P} 19$ & 0,9 & \\
\hline
\end{tabular}

Tabel 2 Data Input Parameter Ketinggian 36.000 feet

\begin{tabular}{|c|c|c|}
\hline Simbol & Nilai & Satuan \\
\hline$M_{0}$ & 0,8 & - \\
\hline$T_{0}$ & 390,33 & ${ }^{\circ} \mathrm{R}$ \\
\hline$T_{t 4}$ & 2769 & ${ }^{\circ} \mathrm{R}$ \\
\hline$P_{0}$ & 3,3 & Psi \\
\hline$\alpha$ & 6 & - \\
\hline$\dot{m}_{0}$ & 852 & lbm $/ \mathrm{s}$ \\
\hline$\pi_{d m a x}$ & 0,995 & - \\
\hline$\pi_{b}$ & 0,95 & - \\
\hline$\pi_{f n}$ & 0,99 & - \\
\hline$\pi_{n}$ & 0,995 & - \\
\hline$\pi_{c}$ & 26,5 & - \\
\hline$\pi_{f}$ & 1,55 & - \\
\hline$e_{c}$ & 0,90 & - \\
\hline$e_{f}$ & 0,89 & - \\
\hline$e_{t}$ & 0,89 & $\mathrm{Btu} /\left(\mathrm{lbm} .{ }^{\circ} \mathrm{R}\right)$ \\
\hline$\gamma_{c}$ & 1,4 & - \\
\hline$C_{p c}$ & 0,24 & $\mathrm{Btu} /\left(\mathrm{lbm} .{ }^{\circ} \mathrm{R}\right)$ \\
\hline$\gamma_{t}$ & 1,333 & $\mathrm{Btu} / \mathrm{lbm}$ \\
\hline$C_{p t}$ & 0,276 & - \\
\hline$h_{P R}$ & 18.400 & - \\
\hline$g_{c}$ & 32,174 & $\left.{ }^{2}\right)$ \\
\hline$\eta_{b}$ & 0,999 & - \\
\hline & & - \\
\hline
\end{tabular}




\begin{tabular}{|c|c|c|}
\hline$\eta_{m}$ & 0,995 & - \\
\hline P0P9 & 0,9 & - \\
\hline P0P19 & 0,9 & - \\
\hline
\end{tabular}

Tabel 3 Data Input Parameter Ketinggian 37.000 feet

\begin{tabular}{|c|c|c|}
\hline Simbol & Nilai & Satuan \\
\hline$M_{0}$ & 0,8 & - \\
\hline$T_{0}$ & 389,97 & ${ }^{\circ} \mathrm{R}$ \\
\hline$T_{t 4}$ & 2769 & ${ }^{\circ} \mathrm{R}$ \\
\hline$P_{0}$ & 3,14 & Psi \\
\hline$\alpha$ & 6 & - \\
\hline$\dot{m}_{0}$ & 852 & $\mathrm{lbm} / \mathrm{s}$ \\
\hline$\pi_{d \max }$ & 0,995 & - \\
\hline$\pi_{b}$ & 0,95 & - \\
\hline$\pi_{f n}$ & 0,99 & - \\
\hline$\pi_{n}$ & 0,995 & - \\
\hline$\pi_{c}$ & 26,5 & - \\
\hline$\pi_{f}$ & 1,55 & - \\
\hline$e_{c}$ & 0,90 & - \\
\hline$e_{f}$ & 0,89 & - \\
\hline$e_{t}$ & 0,89 & - \\
\hline$\gamma_{c}$ & 1,4 & - \\
\hline$C_{p c}$ & 0,24 & $\mathrm{Btu} /\left(\mathrm{lbm} .{ }^{\circ} \mathrm{R}\right)$ \\
\hline$\gamma_{t}$ & 1,333 & - \\
\hline$C_{p t}$ & 0,276 & $\mathrm{Btu} /\left(\mathrm{lbm} .{ }^{\circ} \mathrm{R}\right)$ \\
\hline$h_{P R}$ & 18.400 & $\mathrm{Btu} / \mathrm{lbm}$ \\
\hline$g_{c}$ & 32,174 & lb.ft/(lbf.s $\left.{ }^{2}\right)$ \\
\hline$\eta_{b}$ & 0,999 & - \\
\hline$\eta_{m}$ & 0,995 & - \\
\hline P0P9 & 0,9 & - \\
\hline P0P19 & 0,9 & - \\
\hline
\end{tabular}

Setelah dilakukan perhitungan menggunakan metode Parametric cycle of real engine analysis dengan perubahan nilai bypass ratio dengan variasi ketinggian 35.000, 36.000 dan 37.000 feet, yang dihitung mulai dari nilai konstanta gas di kompresor sampai dengan nilai output di efisiensi total dengan menggunakan siklus parametrik real engine [1] dan di dapatkan salah satu hasil nilai output yaitu, specific fuel consumption yang dapat dilihat pada tabel 4 dan grafik 1 . 
Tabel 4 Hasil Perhitungan SFC Dengan Variasi Ketinggian dan Variasi Bypass Ratio

\begin{tabular}{|c|c|c|c|}
\hline \multicolumn{4}{|c|}{ Specific Fuel Consumption } \\
\hline \multirow{2}{*}{ Bypass Ratio } & \multicolumn{3}{|c|}{ Variasi Ketinggian } \\
\cline { 2 - 4 } & 35000 feet & 36000 feet & 37000 feet \\
\hline 5 & 0,7503 & 0,7512 & 0,7513 \\
\hline 6 & 0,7126 & 0,7134 & 0,7135 \\
\hline 7 & 0,6799 & 0,6806 & 0,6807 \\
\hline 8 & 0,6517 & 0,6522 & 0,6523 \\
\hline
\end{tabular}

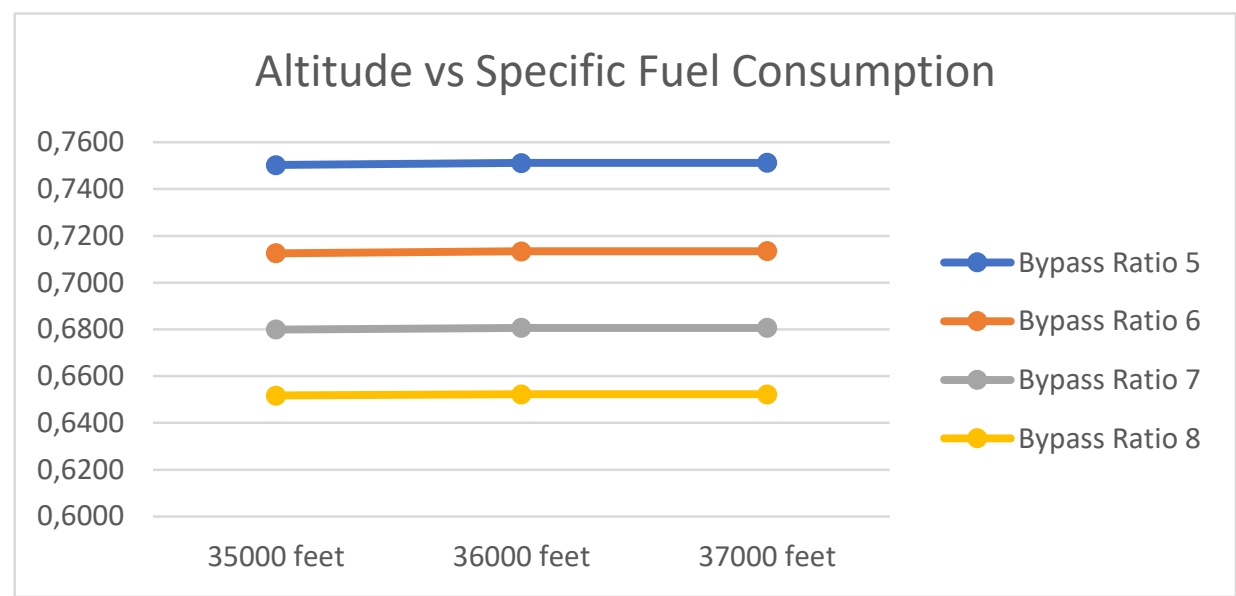

Grafik 1 Hasil Perhitungan SFC Dengan Variasi Ketinggian dan Variasi Bypass Ratio

Hasil perhitungan tabel 3.4 dan grafik 3.1 menunjukkan bahwa semakin tinggi nilai bypass ratio maka nilai specific fuel consumption akan semakin kecil dan semakin tinggi altitude maka nilai specific fuel consumption juga akan semakin kecil, untuk nilai optimum bypass ratio sendiri tetap akan mengacu sesuai engine specification data meskipun nilai bypass ratio maksimum seperti pada table 3.4 akan menghasilkan nilai specific fuel consumption semakin rendah, akan tetapi jika nilai bypass ratio terlalu besar maka akan merubah dimensi dari konstruksi core engine CFM56-5A1 yang kemungkinan besar tidak akan bisa memenuhi performa untuk membuat pesawat bisa terbang pada ketinggian tertentu.

\section{Kesimpulan}

Berdasarkan hasil perhitungan, nilai specific fuel consumption akan semakin kecil jika nilai bypass ratio semakin besar dan nilai specific fuel consumption semakin kecil jika altitude pesawat semakin tinggi, dikarenakan nilai specific fuel consumption dipengaruhi oleh udara yang masuk ke dalam core engine CFM56-5A1, semakin tinggi pesawat maka nilai kerapatan udara akan semakin kecil, dan semakin tinggi nilai bypass ratio maka untuk mencapai suhu maksimum Tt4 yang diijinkan tidak perlu menggunakan fuel yang terlalu besar. Untuk ketinggian optimum pada saat nilai mach yaitu pada saat ketinggian 36.000 feet [3]. 


\section{Daftar Pustaka}

[1] Mattingly, Jack. D. 2006. Elements Of Propulsion : Gas Turbine and Rockets. AIAA Education Series.

[2] Lufthansa Technical Training, 1995, “Data Training Manual CFM56-5A1”, Hamburg. US.

[3] Mallinge, Yannick. 2016, "Safety First", The Airbus Safety Magazine

[4] Ebeling, Charles E., 1997. "An Introduction to Reliability And Maintainability Engineering", The McGraw-Hill Companies, Singapore.

[5] Priyanta, Dwi. 2000. Keandalan Dan Perawatan. Surabaya: Institut Teknologi Surabaya 